\title{
Linfoma Difuso de células B Leg Type
}

\author{
Diffuse B-cell lymphoma Leg Type
}

\author{
Linfoma difuso de células B Tipo de pierna
}

Brenda Maia do Nascimento ${ }^{1 *}$ Emanuel Pereira dos Santos ${ }^{1}$, Vera Lúcia Freitas ${ }^{1}$, Clarissa Coelho Vieira Guimarães ${ }^{1}$, Luiz Alberto de Freitas Felipe ${ }^{1}$, Tamires Zêba Guimarães ${ }^{1}$, Maristela Moura Berlitz ${ }^{1}$ Elizabeth Kölblinger Pereira Gonçalves ${ }^{2}$, Júlya de Araujo Silva Monteiro ${ }^{1}$, Cássio Baptista Pinto'.

\section{RESUMO}

Objetivo: Aprofundar o conhecimento em relação à doença para melhor desenvolver as habilidades técnicocientíficas necessárias ao cuidado de qualidade. Detalhamento do caso: O paciente do presente estudo é do sexo masculino, 75 anos, hipertenso, diabético, com doença linfoproliferativa em investigação há um ano com lesões infiltrantes em MID, que progrediram para lesões em região axilar e inguinal. Essa progressão deveu-se ao fato da primeira antibioticoterapia prescrita não ter sido eficaz, culminando com uma piora progressiva do quadro. Considerações finais: A experiência contribuiu para o aprendizado sobre a patologia e todo o planejamento de cuidados. Também alertou para a importância da investigação clínica minuciosa nessas situações, visto a solução do caso apenas com a conduta clínica correta para um caso de Linfoma, ou seja, é preciso tratar a doença de base para se ter resultados sistêmicos. A união da prática com o estudo do caso foi fundamental para a compreensão do tratamento, tanto medicamentoso como relacionado às lesões, e compreensão mais aprofundada sobre exames laboratoriais. Além disso, contribuiu para a maior compreensão e adoção da humanização no cuidado.

Palavras-chave: Linfoma não Hodgkin, Relatos de casos, Saúde.

\begin{abstract}
Objective: To deepen the knowledge to better develop the technical-scientific skills necessary for quality care. Details of the case: The patient in the present study is male, 75 years old, hypertensive, diabetic, with lymphoproliferative disease under investigation for a year with infiltrating lesions in MID, which progressed to lesions in the axillary and inguinal region. This progression was due to the fact that the first antibiotic therapy prescribed was not effective, culminating in a progressive worsening of the condition. Final considerations: The experience contributed to learning about the pathology and the entire care planning. He also warned of the importance of thorough clinical investigation in these situations, given that the solution of the case only with the correct clinical conduct for a case of lymphoma, that is, it is necessary to treat the underlying disease to have systemic results. The combination of practice with the case study was fundamental for understanding the treatment, both drug-related and related to injuries, and a deeper understanding of laboratory tests. In addition, it contributed to a greater understanding and adoption of humanization in care.
\end{abstract}

Key words: Non-Hodgkin's Lymphoma, Case reports, Health.

\footnotetext{
${ }^{1}$ Universidade Federal do Estado do Rio de Janeiro (UNIRIO), Rio de Janeiro - RJ.

*E-mail: brendamaia1512@gmail.com

${ }^{2}$ Hospital Federal de Bonsucesso, Rio de Janeiro - RJ.
}

SUBMETIDO EM: 1/2021

ACEITO EM: 3/2021

PUBLICADO EM: 4/2021 


\section{RESUMEN}

Objetivo: Profundizar los conocimientos en relación a la enfermedad para desarrollar mejor las habilidades técnico-científicas necesarias para una atención de calidad. Detalles del caso: El paciente del presente estudio es un varón de 75 años, hipertenso, diabético, con enfermedad linfoproliferativa en investigación desde hace un año con lesiones infiltrantes en MID, que evolucionaron a lesiones en región axilar e inguinal. Esta progresión se debió a el hecho de que la primera terapia antibiótica prescrita no fue efectiva, culminando con un empeoramiento progresivo de la condición. Consideraciones finales: La experiencia contribuyó al conocimiento de la patología y de toda la planificación asistencial. También advirtió de la importancia de una investigación clínica exhaustiva en estas situaciones, dado que la solución del caso solo con la correcta conducta clínica para un caso de linfoma, es decir, es necesario tratar la enfermedad de base para tener resultados sistémicos. La combinación de la práctica con el estudio de caso fue fundamental para comprender el tratamiento, tanto relacionado con las drogas como con las lesiones, y una comprensión más profunda de las pruebas de laboratorio. Además, contribuyó a una mayor comprensión y adopción de la humanización en el cuidado.

Palabras clave: Linfoma no Hodgkin, Informes de casos, Salud.

\section{INTRODUÇÃO}

Diversas patologias oncológicas são vistas cada vez mais na prática assistencial. Segundo dados do Instituto Nacional do Câncer (INCA) (2015) no Brasil, estimou-se a ocorrência de 596.070 novos casos de câncer entre 2016 e 2017. E para atender adequadamente a essa demanda, os profissionais da equipe Multiprofissional precisam portar de conhecimento científico e habilidades técnicas necessárias. A Equipe de Enfermagem está com o paciente nas $24 \mathrm{~h}$ e, portanto, precisa se calçar de todo o conhecimento e habilidade necessários à assistência desses pacientes.

Um caso chamou a atenção da Equipe Multiprofissional na vivência assistencial, e deu origem a esse estudo. O diagnóstico médico foi de um Linfoma Difuso de células B Leg Type, de difícil diagnóstico e manejo clínico, principalmente em relação às lesões apresentadas. Segundo Figueira SMV (2012), os linfomas têm origem nas células do sistema linfoide e resultam do acúmulo de linfócitos malignos nos gânglios linfáticos. Cerca de $95 \%$ têm origem em células B e o restante em células T ou NK (natural killer).

O Linfoma de Células B são do tipo Não Hodgkin (LNH). Segundo Freitag MA (2019) o LNH de Grandes Células B corresponde a $90 \%$ dos casos de linfomas agressivos. Geralmente se instala de forma repentina, com crescimento linfonodal rápido na região cervical ou do abdome (linfonodos retroperitoneais ou mesentéricos). Em $40 \%$ dos casos, a apresentação é extranodal, com preferência pelo trato gastrointestinal (estômago, delgado e cólon).

Em 2020, a estimativa de novos casos de LNH no Brasil foi de 12.030, sendo 6. 580 para homens e 5.450 para mulheres (INCA, 2019). É o 6 o tipo de câncer mais comum nos EUA, representando $5 \%$ de todos os novos tumores nos EUA, e 4\% de todas as mortes por câncer no país (WITZIG TE, 2018). Atinge pessoas de diversas faixas etárias, incluindo os jovens. Também não há diferença entre os sexos, sendo que homens e mulheres desenvolvem a doença em proporções semelhantes (FERREIRA ES, 2013).

Pouco ainda se sabe sobre o Linfoma Difuso de células B Leg Type na prática clínica. Portanto o objetivo do estudo foi aprofundar o conhecimento em relação à doença para melhor desenvolver as habilidades técnico-científicas necessárias ao cuidado de qualidade.

\section{DETALHAMENTO DE CASO}

Trata-se do cuidado de enfermagem prestado ao paciente com Linfoma Difuso de células B Leg Type do sexo masculino, 75 anos, hipertenso, diabético, com doença linfoproliferativa em investigação há 1 ano com lesões infiltrativas em membro inferior direito, apresentando infecção secundária, em região axilar e inguinal, 
com internação recente em 27/03/2019, onde realizou biópsia da lesão em MID, com resultado de doença linfoproliferativa. Retornou à unidade em 10/04/2019 com agravamento do quadro. Portanto a conduta foi internação para investigação de Doença Linfoproliferativa, sendo iniciado o tratamento farmacológico com Tazocin associado à Teicoplanina. Foi realizada nova biópsia para diagnóstico do quadro no momento da internação, e o resultado foi liberado em 25/04 onde a imunohistoquímica indicou Linfoma difuso de grandes células B Leg Type.

O manejo clínico do caso estudado foi complexo, necessitando de minucioso planejamento dos cuidados de enfermagem que foram prestados. Havia várias lesões extensas e profundas, sem um diagnóstico definitivo, afinal eram necessários exames complementares para sua definição. Em situações como essa, a equipe de enfermagem precisa estar apta a compreender as necessidades do paciente, e o Enfermeiro precisa de uma visão holística e capacidade técnica atrelada a conhecimento científico suficiente para realizar um plano de cuidados adequado.

A Figura 1, Figura 2 e Figura 3 mostram as lesões do paciente. O mesmo assinou Termo de Consentimento Livre Esclarecido (TCLE), sendo autorizado a divulgação das imagens.

Figura 1 - Lesão em MID extensa em região tíbio-társica, até 1/3 inferior da coxa
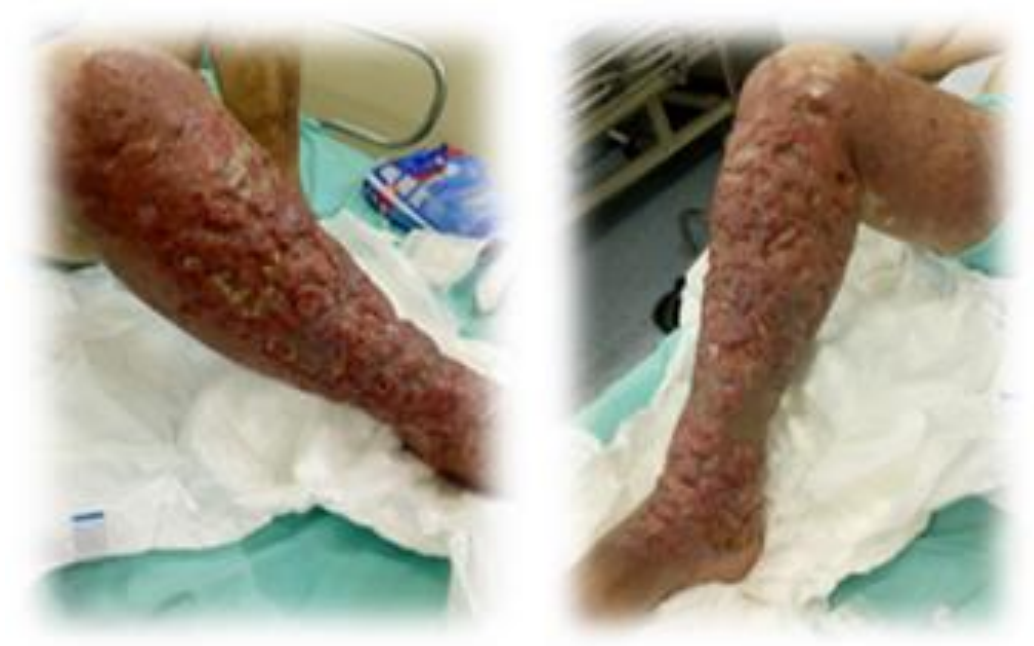

Fonte: Nascimento BM, et al., 2021.

Figura 2 - Lesão Axilar Esquerda cavitária, com bordas elevadas, granulação, esfacelo e exsudato seropurulento em grande quantidade.

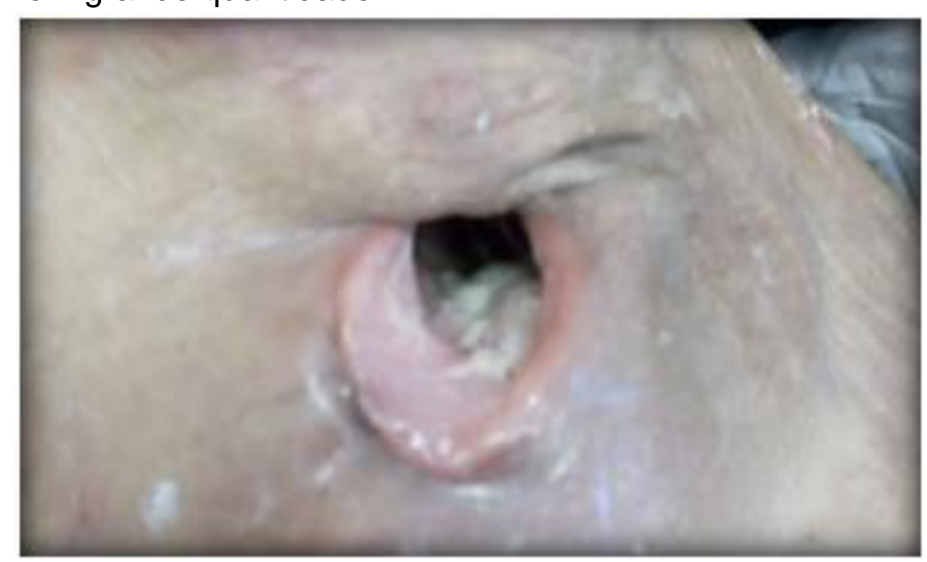

Fonte: Nascimento BM, et al., 2021. 
Figura 3 - Lesão Inguinal Direita com bordas elevadas, leito com esfacelo, exsudato purulento.

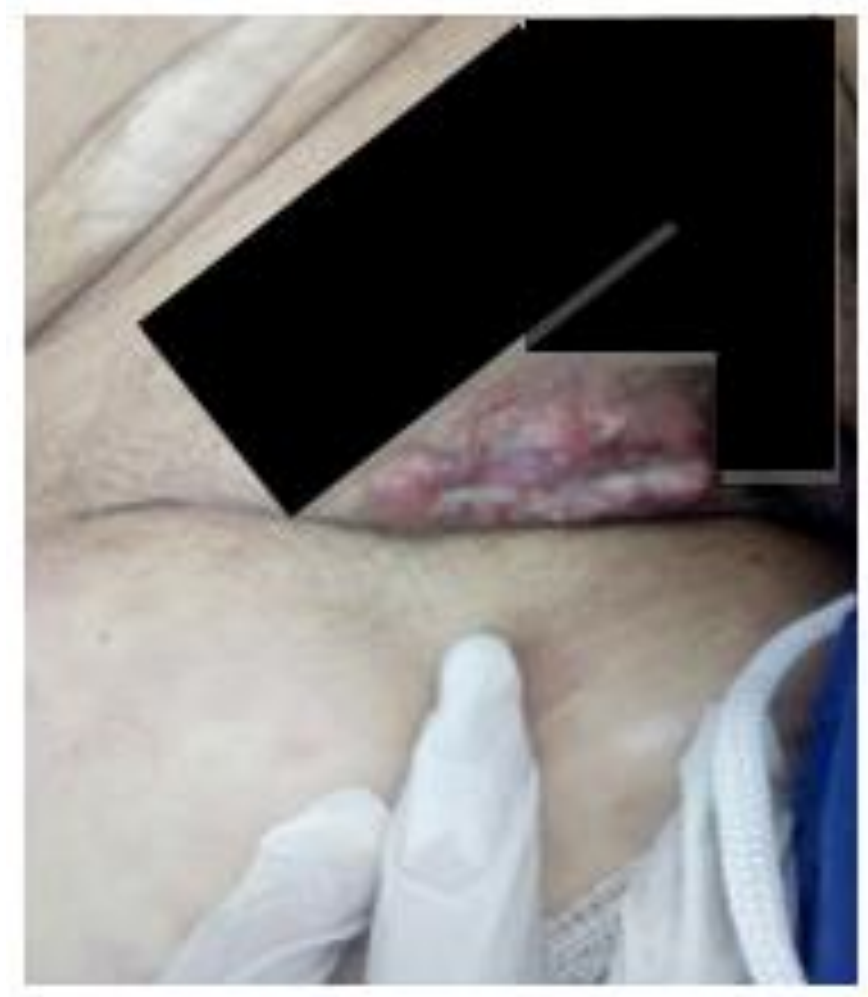

Fonte: Nascimento BM, et al., 2021.

Os principais diagnósticos de enfermagem relacionados ao quadro clínico foram: integridade da pele prejudicada, infecção, risco de queda, conforto prejudicado e deambulação prejudicada.

Os cuidados de enfermagem aplicados ao paciente foram: realizar curativos em técnica asséptica conforme descrição em evolução, realizar troca do curativo em caso de saturação, registrar procedimento e evolução das lesões em prontuário, realizar curva térmica, avaliar exames laboratoriais atentando para leucograma, seguir antibioticoterapia prescrita, orientar quanto aos riscos de queda e como evitá-los, oferecer ajuda para deambulação, oferecer ajuda para banho de aspersão, manter grades do leito elevadas, orientar sobre posicionamento no leito, orientar elevar membros inferiores, avaliar a dor em MID em escala numérica a cada 12h, administrar analgésico SOS para melhor controle da dor e propiciar conforto, manter o paciente o mais próximo do banheiro para reduzir a distância de percurso, disponibilizar andador quando possível, auxiliar na deambulação quando solicitado pelo paciente.

Pelo fato de as lesões serem muito secretivas, o intervalo de troca do curativo era a cada $12 \mathrm{~h}$. O odor era fétido, principalmente na lesão axilar. Mesmo com tanto desconforto relacionado às lesões, o paciente deambulava quando necessário e praticava seu autocuidado.

As lesões eram lavadas com soro fisiológico 0,9\% com exceção do MID que foi higienizado com clorexidina degermante por duas vezes por indicação da Comissão de Curativos, como mostra a Figura 4. As coberturas utilizadas foram Sulfadiazina de prata $1 \%$ na perna e na região inguinal, e carvão ativado com prata na axila. Foi utilizado também, por indicação da Comissão, Durafiber Ag na perna, porém sem sucesso, sendo mantido a Sulfadiazina. Vale ressaltar o nível de dor relatado pelo paciente, numa escala numérica de 5/10.

Esses momentos de avaliação pela Comissão de Curativos eram fundamentais para a troca de informações e ganho de conhecimento, tornando a experiência ainda mais produtiva. O contato diário com o paciente também trouxe enorme aprendizado relacionado à humanização. 
Figura 4 - Higienização com esponja de clorexidina degermante.

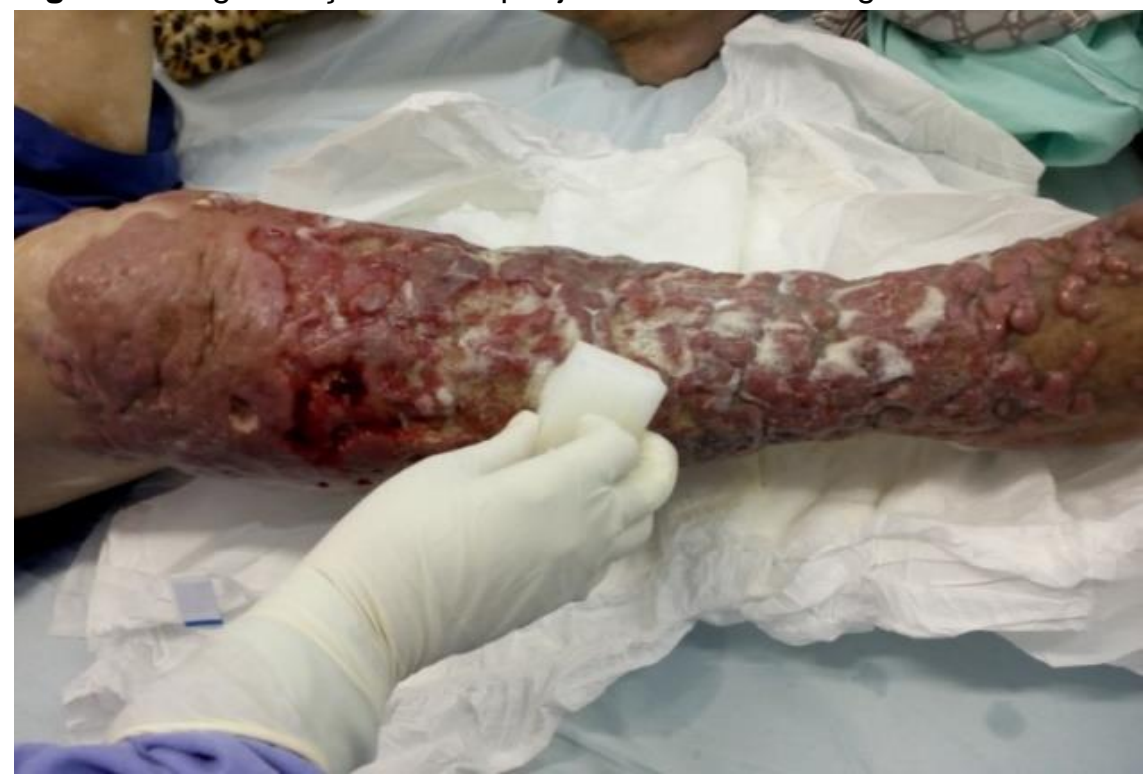

Fonte: Nascimento BM, et al., 2021.

Nos exames laboratoriais, o paciente apresentava leucocitose e hiperglicemia no início da internação, sendo normalizados durante o período. Em 25/04 o resultado da imunohistoquímica indicou Linfoma difuso de grandes células B Leg Type e no dia 30/04 o paciente foi transferido para uma instituição de saúde de tratamento oncológico.

Após 6 meses, foi possível o reencontro com o paciente, em sua reavaliação no ambulatório de dermatologia do Hospital Federal onde esteve internado inicialmente. O mesmo estava realizando as sessões de quimioterapia na devida instituição de tratamento oncológico, e suas lesões tinham cicatrizado como mostra a Figura 5 e Figura 6.

Figura 5 - Cicatrização MID e Axilar E.
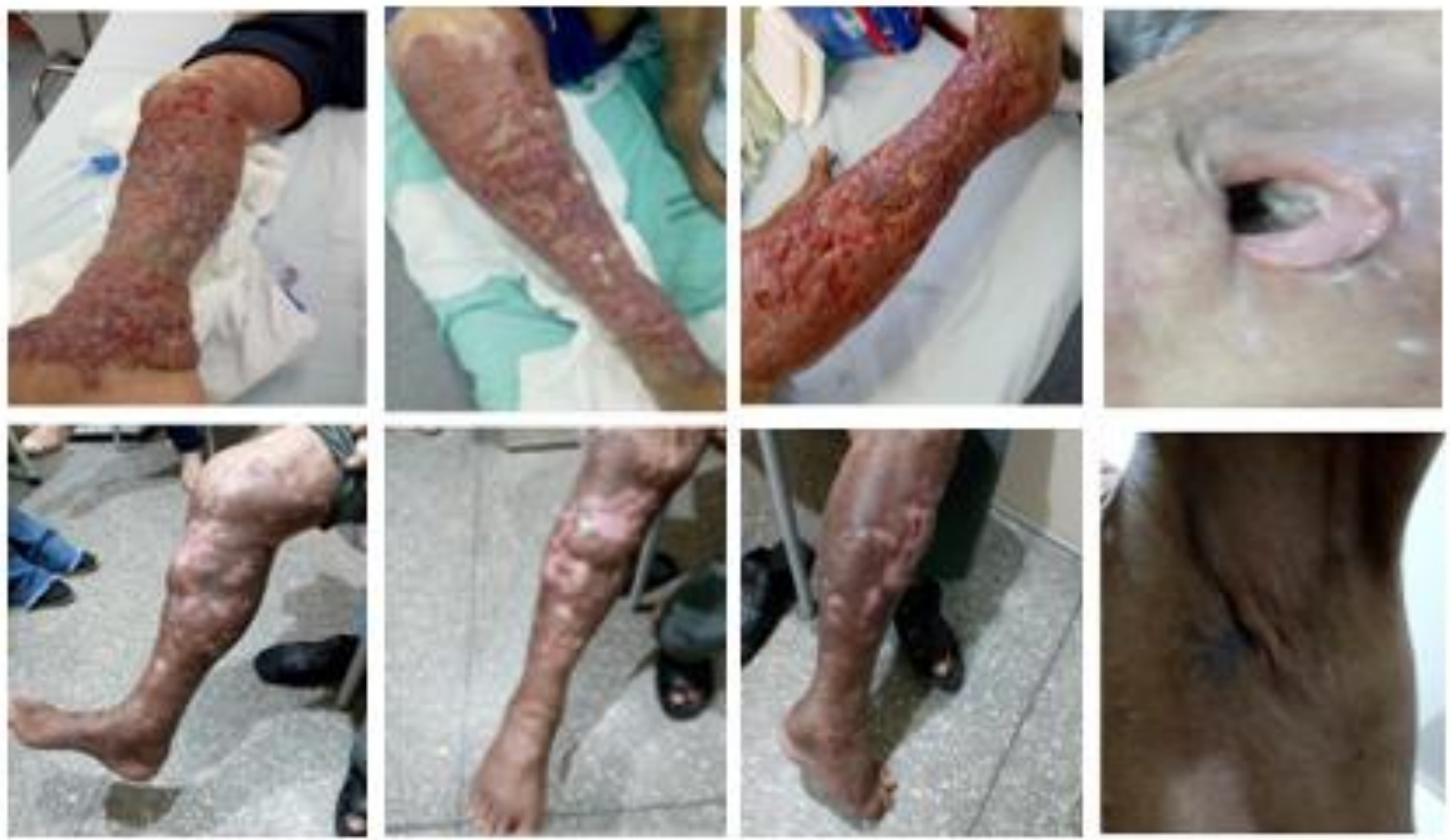

Fonte: Nascimento BM, et al., 2021. 
Figura 6 - Inguinal D.

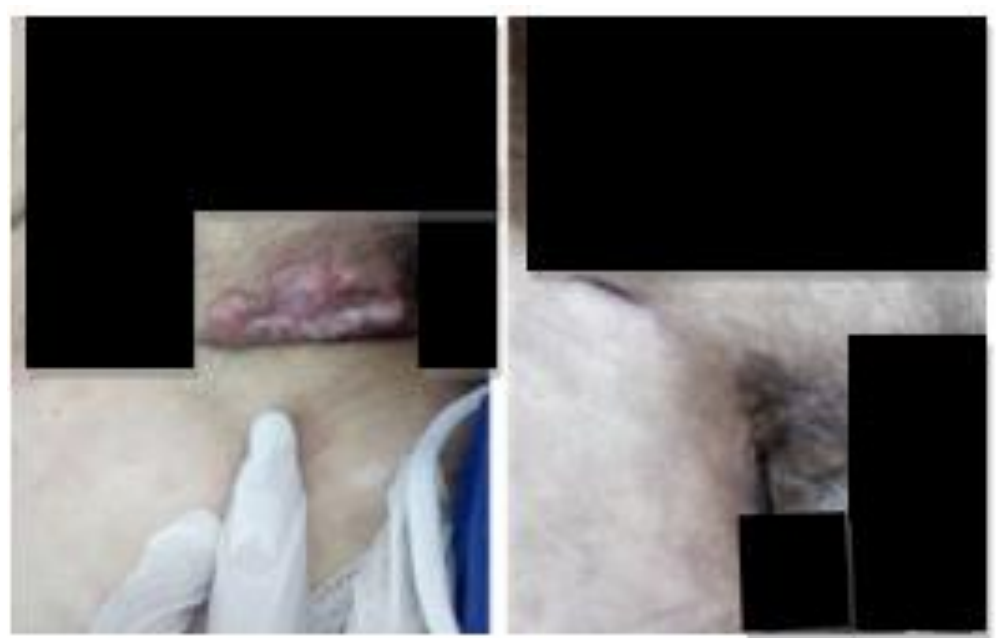

Fonte: Nascimento BM, et al., 2021.

A excelente cicatrização das lesões do paciente evidencia a importância do tratamento oncológico adequado. Sem ele, pode-se usar a melhor cobertura, mas a lesão não irá cicatrizar. O problema do paciente não será resolvido, pois se trata de feridas oncológicas. Portanto é necessária a resolução do desencadeante das lesões, ou seja, a doença oncológica.

A experiência contribuiu para o aprendizado sobre a patologia e todo o planejamento de cuidados. $O$ trabalho diário realizado com a Equipe Multiprofissional, e com o apoio da Comissão de Curativos proporcionou o desenvolvimento de habilidades técnico-científicas inerentes ao caso, servindo também de base para outras situações clínicas. A união da prática com o estudo do caso foi fundamental para a compreensão do tratamento, tanto medicamentoso como relacionado às lesões. Além disso, contribuiu para a maior compreensão e adoção da humanização no cuidado.

\section{DISCUSSÃO}

De acordo com o site do Instituto Oncoguia (2018), o Linfoma Difuso de células B corresponde cerca de $30 \%$ dos casos de Linfoma não-Hodgkin (LNH), apresentando-se principalmente em pessoas em torno de 60 anos. Geralmente se inicia como uma massa de crescimento rápido em órgãos como intestinos, ossos, cérebro, medula espinhal, ou em um linfonodo. Possui crescimento rápido, porém responde bem ao tratamento.

A fisiopatologia ocorre nas fases de maturação. Segundo Castro DLV, et al. (2015), as células progenitoras dos linfócitos $B$ (LB) permanecem na medula óssea durante as fases da maturação. E nessas fases, elas se malignizam no órgão linfóide primário. Depois de maduros, os LB são liberados no sangue periférico desenvolvem-se nos órgãos linfóides secundários como linfonodos, tonsilas palatinas e baço.

As características histológicas são típicas e dão o diagnóstico: os vasos dérmicos e subcutâneos estão dilatados e preenchidos por grandes células neoplásicas, com acúmulos focais extravasculares. São caracterizados por proliferação difusa ou nodular confluente que ocupa maciçamente a derme reticular, infiltrando o tecido adiposo subjacente. $O$ tumor é constituído por grandes células linfóides, às vezes acompanhadas de pequenas células, misturadas ou formando uma borda periférica (RODRÍGUEZ IC, et. al., 2011).

De acordo com Sartor JP e Granemann MA (2007) alguns fatores de risco são: AIDS, transplantados, deficiências imunes congênitas, agentes infecciosos e doenças autoimunes. Além disso, para Petroianu $A$, et al. (2020), a associação de substâncias tóxicas na etiopatogênese do LNH é muito provável.

As manifestações clínicas dependem do órgão afetado, porém, alguns sinais comuns incluem redução de peso, sudorese noturna, anorexia; linfadenopatia cervical, inguinal ou axilar (GOMES FRT, 2019). 
Pelas diferentes variantes de linfomas cutâneos, aconselha-se que os processos de diagnóstico e tratamento sejam realizados em centros especializados e com dermatologistas, hematologistas e patologistas. Intervenções psicossociais são pertinentes, resultando em melhoria do bem-estar geral e na qualidade de vida (SOLHA IISG, 2012).

A rotina diagnóstica nos processos linfoproliferativos de células $B$ é realizada pela biópsia da pele lesada para a análise histopatológica e imunohistoquímica (MORICZ CZM e JÚNIOR JAS, 2005). Histopatologicamente, mostra infiltrado de células grandes atípicas (RIZO VHT, 2013).

No caso do paciente que deu origem ao estudo, o diagnóstico foi através da imuno-histoquímica. Para tanto, o paciente foi internado para investigação. Para Caly A, et al. (2013) a investigação clínica promove um diagnóstico mais preciso e orienta quais são os casos de uma investigação mais específica. A avaliação histopatológica é fundamental para determinar o tipo e classificação histológica, orientando a proposta e conduta terapêutica. A imuno-histoquímica é muito utilizada nos casos de linfomas, para melhor abordagem diagnóstica na diferenciação entre linfomas de Hodgkin, não Hodgkin B e T, e melhor subtipagem. Portanto é praticamente incabível que sua conclusão diagnóstica ocorra sem uma confirmação de imuno-histoquímica.

Um dos principais sinais do Linfoma Cutâneo é a linfadenopatia. Como foi visto em imagens nesse estudo, as feridas oncológicas oriundas da linfadenopatia podem ser profundas e extensas. De acordo com Woo KY e Sibbald RG (2010), as etapas de formação das feridas oncológicas são: crescimento tumoral, neovascularização e invasão da membrana basal da célula. Caracterizam-se por odor fétido, dor, hemorragias, exsudação abundante, infecções, prurido e não cicatrizam.

O conhecimento sobre as feridas cutâneas malignas e como proceder na sua avaliação e tratamento são decisivos na atuação dos enfermeiros. Acredita-se que o cuidado de pessoas com lesões malignas realizados por enfermeiros inseridos na saúde pública sofre a influência de problemas relacionados à carência de recursos materiais e de medicamentos necessários à terapêutica disponíveis nas unidades de saúde, além de deficiências na capacitação e qualificação profissional, comprometendo a assistência aos portadores da patologia. Dentre os tipos de tratamento, a terapia tópica destaca-se por ser mais acessível, envolver produtos diversificados e ter baixo custo em relação às demais alternativas de tratamento. Essa corresponde basicamente à utilização de curativos e coberturas (AZEVEDO IC, et al., 2014). Relacionado ao caso apresentado no estudo, a terapia tópica foi o principal ponto dos Cuidados de Enfermagem.

Em feridas oncológicas, o conforto e a manutenção da dignidade são os principais objetivos. Os cuidados são para o alívio dos sintomas de dor, odor, sangramento, exsudato e prurido (SANTOS MJ, 2013). Para tanto, é necessária a correta avaliação, para a melhor escolha da cobertura a se utilizar.

Em relação ao tratamento, conforme publicação do Instituto Oncoguia (2017), se o linfoma estiver localizado em apenas uma ou poucas áreas, é comumente realizada a radioterapia, mas caso ocorra disseminação para os linfonodos ou outros órgãos, os pacientes precisam de quimioterapia sistêmica.

$\mathrm{O}$ tratamento, baseado na utilização da poliquimioterapia associada ou não à radioterapia, tem proporcionado altas taxas de cura. No caso do $\mathrm{LNH}$, especialmente o linfoma difuso de grandes células $\mathrm{B}$, a associação dos antineoplásicos ciclofosfamida, doxorrubicina, vincristina e prednisona (CHOP) tem apresentado elevadas taxas de resposta e cura, sendo menos comuns as reações tóxicas fatais. Adicionalmente, a associação dessas drogas com o rituximab (anticorpo monoclonal anti-CD20) parece incrementar as taxas de resposta e cura para o LNH derivados de células B (MARCONDES JPC, 2011).

De acordo com o site A. C. Camargo (2015), o rituximabe é indicado para o tratamento do linfoma difuso de grandes células $B$, que corresponde a cerca de $30 \%$ de todos os linfomas, e também para os pacientes com linfoma não Hodgkin de células B folicular em primeira e segunda linha.

Aumentando as opções terapêuticas nesse cenário, em 31 de julho de 2020, o FDA (Food and Drug Administration) aprovou o uso do anticorpo monoclonal humanizado anti-CD19 tafasitamab-cxix em combinação a lenalidomida para o tratamento de pacientes portadores de linfoma não Hodgkin difuso de células $B$ grandes (LDCBG) recidivado ou refratário em casos não elegíveis para transplante de medula óssea autólogo (MOC, 2020). 
Diante das informações, compreende-se a capacidade de rápido crescimento do Linfoma Difuso de células B no organismo. Mas apesar disso, responde positivamente aos tratamentos quimioterápicos existentes.

A experiência contribuiu para o aprendizado sobre a patologia e todo o planejamento de cuidados, além de enfatizar a importância da humanização no cuidado. Também alertou para a importância da investigação clínica minuciosa nessas situações, visto a solução do caso apenas com a conduta clínica correta para um caso de Linfoma, ou seja, é preciso tratar a doença de base para se ter resultados sistêmicos. A união da prática assistencial com o estudo do caso foi fundamental para a compreensão do tratamento, tanto medicamentoso como relacionado às lesões, e dessa forma, enriquecendo a Enfermagem de mais conhecimento científico.

\section{FINANCIAMENTO}

Financiado por Ministério da Saúde através de bolsa de Residência em Enfermagem.

\section{REFERÊNCIAS}

1. A.C. CAMARGO CANCER CENTER. 2015. Após 7 anos, OMS atualiza classificação dos linfomas e patologistas de 9 países debatem em SP os novos critérios. Disponível em: https://www.accamargo.org.br/sobre-ocancer/noticias/apos-7-anos-oms-atualiza-classificacao-dos-linfomas-e-patologistas-de-9. Acesso em: 18 jan. 2021.

2. AZEVEDO IC, et al. Tratamento De Feridas: A Especificidade Das Lesões Oncológicas. Revista Saúde e Pesquisa, 2014; 7(2): 303-313.

3. BRASIL. Manual do Ministério da Saúde. $2015 . \quad$ Disponível em: https://www.inca.gov.br/bvscontrolecancer/publicacoes/edicao/Estimativa_2016.pdf. Acesso em: 18 jan. 2021.

4. BRASIL. Manual do Ministério da Saúde. 2020. Disponível em: Disponível em: https://www.inca.gov.br/tipos-decancer/linfoma-nao-hodgkin. Acesso em: 18 jan. 2021.

5. BRASIL. Manual de Oncologia Clínica do Brasil (MOC). Anticorpo anti-CD19 aprovado para o tratamento de linfoma difuso de células B grandes nos EUA. 2020. Disponível em: https://mocbrasil.com/blog/neoplasiashematologicas/linfomas/anticorpo-anti-cd19-aprovado-para-o tratamento-de-linfoma-difuso-de-celulas-b-grandesnos eua/?utm_source=rss\&utm_medium=rss\&utm_campaign=anticorpo-anti-cd19-aprovado-para-o-tratamento-delinfoma-difuso-de-celulas-b-grandes-nos-eua. Acessado em: 18 de janeiro de 2021.

6. CALY DN, et al. Papel da imuno-histoquímica no diagnóstico de adenopatias cervicais malignas. Revista Brazilian Journal of Otorhinolaryngology, 2013; 79(5): 625-628.

7. CASTRO DLV. Linfoma Cutâneo: um Câncer de Pele Pouco Conhecido. Revista da Associação Brasileira de Estomaterapia, 2015; 13(4): 1-5.

8. FERREIRA ES. Perfil Clínico-Epidemiológico De Linfoma Não-Hodgkin E A Prevalência Da Infecção Pelo Vírus Da Imunodeficiência Humana (Hiv) Em Pacientes Atendidos Em Belém-Pará. Dissertação (Mestre em Biologia de Agentes Infecciosos e Parasitários) - Instituto De Ciências Biológicas. Universidade Federal Do Pará, Belém, 2013; $74 p$.

9. FIGUEIRA SMV. Linfomas Não-Hodgkin Agressivos. Dissertação (Mestre em Medicina) - Faculdade De Medicina Da Universidade De Coimbra, Coimbra, 2012; 90p.

10. FREITAG FM, et al. Linfoma Não-Hodgkin De Células B: Relato De Caso. Revista Thêma et Scientia, 2019; 9(1): 200 $-208$.

11. GOMES RFT. Linfoma nãoHodgkin, manifestação no sistema estomatognático - Relato de caso clínico. Revista Saúde (Sta. Maria), 2019; 45 (3): 1 - 7.

12. HERDMAN TH, KAMITSURU S. Diagnósticos de Enfermagem da NANDA - I Definições e Classificação.11 nd ed. 2018; 488p.

13. INSTITUTO ONCOGUIA. 2017. In: Tratamento para Tipos Específicos de Linfoma de Pele. Disponível em: http://www.oncoguia.org.br/conteudo/tratamento-para-tipos-especificos-de-linfoma-de-pele/4910/649/. Acesso em: 18 jan. 2021.

14. INSTITUTO ONCOGUIA. 2018. In: Tipos de Linfomas não Hodgkin de Células B. Disponível em: http://www.oncoguia.org.br/conteudo/tipos-de-linfomas-nao-hodgkin-de-celulas-b/12258/52/. Acesso em: 18 jan. 2021.

15. MARCONDES JPC. Efeitos Toxicogenômicos Tardios De Terapias Antineoplásicas Para Linfomas. Tese (Doutorado em Patologia) - Universidade Estadual Paulista "Júlio De Mesquita Filho", Botucatu, 2011; 84p.

16. MORICZ CZM, Júnior JAS. Processos linfoproliferativos da pele. Parte 1 - Linfomas cutâneos de células B. An. Bras. Dermatol, 2005; 80(5): 461 - 471.

17. PETROIANU A, et al. Comparação Etiopatogênica, Epidemiológica E Clinicoterapêutica De Linfoma Não Hodgkin E Sarcoma De Kaposi. Revista ABCD. Arquivos Brasileiros de Cirurgia Digestiva, São Paulo, 2020; $33(2): 1$ - 4.

18. RIZO VHT. Hodgkin / Reed-Sternberg-Like Cells In Diffuse Large B Cell Lymphoma Of The Oral Cavity: Histopathological, Immunohistochemistry And In Situ Hybridization Study. Tese (Doutorado em Estomatopatologia na Área de Patologia) - Universidade Estadual de Campinas, Piracicaba, 2013; 135p. 
19. RODRÍGUES IC, et al. Linfoma cutâneo de grandes células B das pernas: relato de caso. Revista Camaguey Medical Archive, 2011;15(6): 1-9.

20. SARTOR JP, GRANEMANN MA. Guia Prático de Hematologia. Linfoma Não- Hodgkin. 2007. Disponível em: http://repositorio.unesc.net/bitstream/1/7462/1/cap\%C3\%ADtulo\%2007.pdf. Acessado em: 18 de janeiro de 2021.

21. SANTOS MJ. Feridas Oncológicas Em Cuidados Paliativos. Trabalho de Conclusão de Curso (Especialização em Enfermagem em Estomaterapia) - Unidade de Educação Continuada. Universidade do Vale do Rio dos Sinos, Porto Alegre, 2013; 20p.

22. SOLHA IISG. Sofrimento Emocional Em Doentes Oncológicos: Experiência De Uma Consulta De Linfomas Cutâneos. Dissertação (Mestrado Integrado em Medicina) - Instituto de Ciências Biomédicas Abel Salazar. Universidade do Porto, Porto, 2011/2012; 64p.

23. WOO KY, SIBBALD RG. Local wound care for malignant and palliative wound. Advances in skin \&wound care, 2010; 23(9): 417-428. 